\title{
FORMAÇÃO DE PROFESSORES DE ESPANHOLPARA CRIANÇAS NO BRASIL: ALGUNS CAMINHOS POSSÍVEIS
}

\author{
SPANISHTEACHER EDUCATIONAND THE TEACHING OFSPANISHTO \\ CHILDREN IN BRAZIL: SOME POSSIBLE WAYS
}

\author{
GRETELERES FERNÁNDEZ \\ SIMONERINALDI**
}

\begin{abstract}
RESUMO: Este trabalho procura delinear a atual situação do ensino de espanhol como língua estrangeira para crianças brasileiras. Partimos das questões legais que envolvem a aprendizagem e o ensino a crianças nos primeiros anos do Ensino Fundamental e que apresentam uma lacuna na qual é possível incluir o ensino de língua estrangeira antes do proposto nas referidas leis. Apoiamo-nos, também, nas teorias de desenvolvimento propostas por Piaget (1967) e Vygotsky (1993) que descrevem as etapas pelas quais as crianças passam. Fundamentamo-nos, ainda, nos postulados sobre aquisição/aprendizagem de línguas estrangeiras de Krashen (1995) bem como na hipótese do input compreensível, na medida em que entendemos que interage com a teoria vygostkyana sobre a zona de desenvolvimento proximal (ZDP). Além disso, tomamos como base os estudos de Cameron (2001) sobre ensino e aprendizagem de línguas estrangeiras para crianças, nos quais são criticados alguns pontos da teoria de Piaget, entre eles a limitação etária que o pesquisador afirmava que as crianças apresentam. Valemo-nos, ainda, do trabalho de Carranza (2002) que concorda com a hipótese do filtro afetivo formulada por Krashen que, segundo aquela pesquisadora, atua diretamente no processo de aquisição da língua estrangeira. Este artigo, com base na pesquisa no qual se apóia, oferece, também, algumas sugestões de atividades para o ensino de línguas estrangeiras para crianças e, por fim, recomenda a implantação de cursos de formação de professores de espanhol como língua estrangeira para crianças, uma vez que, até este momento, não se tem notícia da existência de um programa como esse.
\end{abstract}

Palavras-chave: espanhol para crianças; ensino de espanhol; formação de professores.

RESUMEN: Este trabajo busca delinear la situación actual de la enseñanza de español como lengua extranjera a niños brasileños. Partimos de las cuestiones legales que atañen a la enseñanza y al aprendizaje de niños en los primeros años de la Enseñanza Fundamental y que presentan un hueco en el que se puede incluir la enseñanza de lengua extranjera antes de lo propuesto en las referidas leyes. También nos apoyamos en las teorías de desarrollo de Piaget (1967) y Vygotsky (1994) que describen las etapas por las que pasan los niños. Nos fundamentamos aun en los postulados sobre adquisición/aprendizaje de lenguas extranjeras de Krashen (1995), así como en la hipótesis del input comprensible, en la medida en que entendemos que interactúa con la teoría vygotskyana sobre la zona de desarrollo proximal (ZDP). Además, tomamos como base los estudios de Cameron (2001) sobre enseñanza y aprendizaje de lenguas extranjeras a niños, en los que se critican algunos puntos de la teoría de Piaget, entre ellos la limitación de edad que el investigador afirmaba que los niños presentan. También nos pautamos en el trabajo de Carranza (2002) que está de acuerdo con la hipótesis del filtro afectivo formulada por Krashen que, según

\footnotetext{
*USP, São Paulo (SP), Brasil. <igmefern@usp.br>

** USP, São Paulo (SP), Brasil. <monenaldi@ hotmail.com>
} 
FERNÁNDEZ e RINALDI — Formação de professores de espanhol...

aquella investigadora, actúa directamente en el proceso de adquisición de la lengua extranjera. Este artículo, con base en la investigación en que se apoya, también ofrece algunas sugerencias de actividades para la enseñanza de lenguas extranjeras a niños y, por fin, recomienda la implantación de cursos de formación de profesores de español como lengua extranjera a niños, una vez que, hasta ahora, no se conoce un programa como ese.

Palabras-clave: español para niños; enseñanza de español; formación de profesores.

\section{INTRODUÇÃO}

Durante nossa formação graduada e pós-graduada assim como ao longo de nossa experiência profissional, constatamos que diversas escolas oferecem o ensino de língua espanhola para seus alunos de Educação Infantil e dos primeiros anos do Ensino Fundamental. Por interessar-nos conhecer as motivações e repercussões desse ensino na formação das crianças, realizamos uma investigação, no período de 2004 a 2007, na qual centramos nossa atenção inicialmente na descrição do panorama do ensino de espanhol para essa faixa etária, o que nos levou a analisar o significado que a oferta de uma língua estrangeira (doravante, LE), especificamente do espanhol, poderia assumir nesse nível. Num segundo momento, buscamos conhecer a formação dos professores que atuam em tal segmento, tendo em vista a inexistência de cursos destinados a formar e habilitar docentes de língua espanhola para atuarem com crianças daquela faixa etária.

Neste artigo, discutimos alguns dos argumentos legais para a inclusão de uma língua estrangeira - em nosso caso, o espanhol - no programa curricular dos primeiros anos do Ensino Fundamental. Posteriormente, revisitamos as teorias do desenvolvimento, de aprendizagem em geral e de aquisição/aprendizagem de línguas estrangeiras para, a seguir descrevermos a realidade atual do ensino de espanhol para crianças: quem são seus professores, como eles atuam e quais dificuldades encontram. Por fim, sugerimos algumas estratégias e atividades para um trabalho mais condizente com as teorias de aquisição/ aprendizagem voltadas para o público infantil.

\section{AS LÍNGUAS ESTRANGEIRAS NA EDUCAÇÃO BÁSICA}

No Brasil, diversas escolas particulares e públicas incluem aulas de língua estrangeira a partir das primeiras séries do ensino fundamental, medida que se mostra, por vezes, polêmica, pois há os que defendem o ensino de uma língua estrangeira - ou inclusive mais de uma - em idades precoces, e há os que opinam que tal ensino só deve ocorrer a partir de idades mais avançadas. Os argumentos arrolados por uns e outros são variados e nem sempre facilmente refutáveis. Daí que consideremos relevante discutir alguns dos aspectos que vêm à tona quando pensamos no melhor momento de expor a criança à aprendizagem de um novo idioma.

A Lei $\mathrm{n}^{\circ}$ 9.394, de 20 de dezembro de 1996, que estabelece as diretrizes e bases da educação nacional - LDBEN, ressalta em várias oportunidades a importância dada ao estudo de línguas estrangeiras nos três níveis de ensino da Educação Básica (Educação Infantil, Ensino Fundamental e Ensino Médio). Especificamente em relação ao Ensino 
Fundamental, a referida lei postula que deve ser incluído, obrigatoriamente, a partir da quinta série (atual sexto ano), o ensino de pelo menos uma língua estrangeira à escolha da comunidade escolar, dentro das possibilidades da instituição sem, contudo, restringir explicitamente seu aprendizado a partir desse nível escolar.

Além disso, o texto legal recomenda, como conteúdos curriculares da Educação Básica, que haja uma difusão de valores fundamentais ao interesse social, aos direitos e deveres dos cidadãos, de respeito ao bem comum e à ordem democrática e que se propicie orientação voltada para o trabalho. Estando a língua estrangeira incluída entre os conteúdos curriculares da Educação Básica, pode-se concluir que os relatores do texto legal consideram que o conhecimento de pelo menos um idioma estrangeiro faz parte da formação integral do indivíduo ao mesmo tempo em que auxilia a sua capacitação para o mercado de trabalho.

Dessa forma, podemos depreender que, desde que se obedeça ao currículo mínimo obrigatório, pode-se incluir, sob a égide da parte diversificada, quaisquer disciplinas e, entre elas, uma ou mais línguas estrangeiras nos primeiros anos do Ensino Fundamental, ou ainda, na Educação Infantil, uma vez que o documento legal não proíbe tal oferta.

Contudo, apesar de não haver restrições legais à inclusão de línguas estrangeiras antes do sexto ano, e apesar do crescente número de estabelecimentos escolares que oferecem essa oportunidade aos alunos, essa ainda não é uma prática generalizada.

Assim, por falta de condições, a maioria das escolas da rede pública vê-se forçada a cumprir apenas as diretrizes mínimas oficiais e a oferecer a disciplina língua estrangeira, quase sempre a língua inglesa, somente a partir do sexto ano. Contudo, desde 1987, com a criação dos Centros de Estudos de Línguas no Estado de São Paulo (CEL), os alunos matriculados a partir da sexta série (atual sétimo ano) ${ }^{1}$ têm a oportunidade de estudar outra(s) língua(s) estrangeira(s).

$\mathrm{Na}$ rede particular de ensino, muitas escolas passaram a oferecer, de maneira mais acentuada durante a última década, a língua inglesa como idioma estrangeiro a partir dos primeiros anos do Ensino Fundamental ou mesmo a partir da Educação Infantil. Mais recentemente, algumas delas optaram pela inclusão de uma segunda língua - na maioria dos casos a espanhola - já no sexto ano; e há, ainda, algumas escolas que começaram a adotar o estudo do espanhol, além do inglês, nos primeiros anos do Ensino Fundamental.

Na prática, nota-se que a inserção da língua estrangeira, principalmente a espanhola, está crescendo em todos os níveis que integram a Educação Básica. Tal iniciativa originada em centros escolares vê-se, atualmente e ao menos em parte, respaldada pela sanção da Lei no. 11.161, de 05 de agosto de 2005, que estabelece a oferta obrigatória da língua espanhola no Ensino Médio por todas as escolas brasileiras, ainda que seja opcional ao aluno estudála, e como opcional às escolas a oferta desse idioma a partir do sexto ano do Ensino Fundamental. Muitos colégios estão aproveitando essa oportunidade legal para incluir (ou manter), como diferencial, o idioma espanhol em todos os níveis de ensino.

Vale lembrar, ainda, que uma das reivindicações docentes, explicitadas na Carta de Pelotas, documento elaborado em 2000, propõe a expansão do ensino de línguas estrangeiras às séries iniciais do nível fundamental, tendo em vista, entre outros fatores, o fato de que a

${ }^{1}$ Condição de escolaridade mínima, segundo a Coordenadoria de Estudos e Normas Pedagógicas do Estado de São Paulo, para poder integrar-se aos cursos oferecidos pelos CEL. 
FERNÁNDEZ e RINALDI — Formação de professores de espanhol...

aprendizagem de idiomas faz parte da formação integral do aluno, princípio também assegurado pela legislação em vigor.

\section{ALGUNSPRINCÍPIOS NORTEADORESDOENSINODE LÍNGUASESTRANGEIRAS A CRIANÇAS}

Diferentes documentos oficiais como o "Referencial Curricular Nacional para a Educação Infantil" (BRASIL, 1998), "PCNs: pluralidade cultural, orientação sexual" (BRASIL, 1997) para os primeiros ciclos do Ensino Fundamental e "PCNs: terceiro e quarto ciclos do ensino fundamental: língua estrangeira" (BRASIL, 1998) deixam claro que o poder público incentiva o conhecimento e a aproximação das crianças pequenas com as diversas culturas existentes no país.

Os textos legais reafirmam a importância da linguagem como meio para a apresentação e divulgação das diferentes culturas, porque é por meio dela que o ser humano pode ter acesso a outras realidades sem passar, necessariamente, pela experiência concreta. Com esse recurso, a criança tem acesso a mundos e povos que tanto podem estar relativamente próximos da sua realidade quanto a outros mais distantes, reais e/ou até mesmo imaginários. Dessa forma, ainda que não concretamente, à criança é viável e possível a introdução do idioma estrangeiro como parte de outro(s) contexto(s), pois através da relação precoce (não de maneira pejorativa) com a língua estrangeira a criança pode vir a criar, no seu íntimo, ao longo do seu desenvolvimento intelectual e social, um espaço para abrigar o que lhe for novo - sem rechaçar o desconhecido, sem repelir o diferente, mas ao contrário, com respeito ao que lhe vier a ser diverso.

Uma das formas de imprimir na criança valores não discriminatórios é dar-lhes a oportunidade de, também nos primeiros anos do Ensino Fundamental, conhecer outras culturas por meio do estudo de línguas estrangeiras. Encontramos respaldo legal a essa nossa proposta nos Parâmetros Curriculares Nacionais (doravante PCNs), que afirmam que o conhecimento da existência de outras línguas diferentes da Língua Portuguesa amplia os horizontes das crianças e propicia-lhes entender a complexidade do país, além de promover uma reflexão metalinguística e a compreensão de como são constituídas as identidades e as singularidades de diferentes povos e etnias.

Mantendo uma coerente linha educativa, os "PCNs de Língua Estrangeira" (1998: 19) destinados aos dois últimos ciclos do Ensino Fundamental apóiam-se na relação respeitosa com o outro ao declarar que, quando o aluno usa uma língua diferente da sua aproxima-se do outro falante dessa língua e se afasta de si. Com isso, consegue ter ampliada sua autopercepção como ser humano e cidadão e continua aprendendo mais sobre si mesmo e sobre um mundo plural, marcado por valores culturais diferentes e maneiras diversas de organização política e social.

Tal visão retoma muito do que foi preconizado nos "PCNs da $1^{a}$. à $4^{a}$. série" e também no "Referencial Curricular Nacional para a Educação Infantil": conhecer o outro para conhecer-se melhor, estudar sobre um mundo diverso para aprender a respeitá-lo, a entendêlo e, com isso, tentar banir o preconceito da nossa sociedade. Esforços nesse sentido 
permeiam muitas das disciplinas escolares. Por que não seria igual com a Língua Estrangeira, uma vez que ela, por si só, já é considerada (legitimamente) diferente?

Embora não explicitamente declarado, a inclusão do ensino de língua estrangeira na Educação Infantil assumiria a finalidade de favorecer um primeiro contato lúdico e prazeroso com um novo idioma e com uma nova cultura, além de propiciar a ampliação dos horizontes reais e imaginários dos pequenos. Já nos primeiros anos do Ensino Fundamental esse contato, igualmente lúdico e prazeroso, passaria a auxiliar na percepção e na tolerância das diferenças entre pessoas e formas diferentes de pensar e agir. A inserção obrigatória de uma língua estrangeira nos anos seguintes do Ensino Fundamental estaria voltada ao aprimoramento dessa relação com outras maneiras de se pensar o mundo. Finalmente, no Ensino Médio a(s) língua(s) estrangeira(s) funcionaria como meio de acesso ao conhecimento tecnológico e cultural e a uma melhor inserção do educando num mundo plural e globalizado. Também nestes dois últimos níveis é essencial ter presente a relevância da aprendizagem significativa e, para tanto, aqueles elementos anteriores - ludicidade e prazer - deveriam continuar permeando as aulas do idioma estrangeiro.

Essa linearidade sugerida anteriormente figura também nos textos legais, por exemplo, nos PCNs de Língua Estrangeira destinados aos últimos anos do Ensino Fundamental ao afirmarem que um pressuposto básico para a aprendizagem de uma língua estrangeira é a necessidade de garantir a continuidade e a sustentabilidade de seu ensino.

Dessa forma, vê-se corroborada nossa hipótese acerca da importância da inserção do ensino de línguas estrangeiras, mais precisamente, da língua espanhola, já nas primeiras séries do Ensino Fundamental e até mesmo durante a Educação Infantil. Permitir que o primeiro contato com línguas estrangeiras aconteça naturalmente, ainda que num espaço de aprendizagem formal, através de jogos e brincadeiras, maneira frequente pela qual as crianças aprendem, pode contribuir para se criar uma base sólida de comportamento e de desenvolvimento tanto de conhecimento de outros idiomas quanto de tolerância em relação ao diferente.

No que diz respeito especificamente às questões etárias, pesquisadores como Krashen (1995), Jalles (2003), Schütz (2004) e Rodrigues (2005) concordam que até por volta dos 11 anos as crianças apropriam-se da língua estrangeira de forma mais rápida e eficiente do que os adultos; porém, Krashen e Rodrigues chamam a atenção para alguns aspectos que acrescentam ressalvas a essa afirmativa.

Segundo Krashen (1995), não se trata simplesmente de quanto mais novo melhor porque as crianças superam os adultos somente a longo prazo. Já Rodrigues (2005) afirma que as crianças, quando comparadas aos adultos, parecem apresentar maior índice de aproveitamento em pronúncia quando estão muito expostas à segunda língua, principalmente em situações naturais de aquisição. A pesquisadora reforça que, no entanto, adolescentes e adultos costumam se sobressair nos outros aspectos linguísticos, principalmente em situação formal de aprendizagem, porque conseguem ter maior controle consciente sobre suas atividades cognitivas.

Embora com restrições sobre prazos e aprendizagem de aspectos formais da língua, esses investigadores reafirmam que o desempenho infantil se sobressai ao do adolescente e ao do adulto. Cabe considerar, ainda, que o fator sócio-cultural é preponderante nos 
FERNÁNDEZ e RINALDI — Formação de professores de espanhol...

textos legais brasileiros que tratam do ensino de língua estrangeira, ou seja, a apropriação de um novo idioma abrange questões que vão muito além dos aspectos formais da língua.

Referente especificamente à oferta do ensino de língua estrangeira a crianças de 6 a 10 anos, Solla (2005) lançou algumas perguntas sobre a necessidade ou função desse ensino. A primeira que nos interessa refere-se a uma dúvida muito comum entre os profissionais que lidam com essa faixa etária: antes do sexto ano do ensino fundamental, a criança deve aprender uma língua estrangeira ou deve ser sensibilizada a outras línguas e culturas?

Boéssio (2005), com quem concordamos, nos responde que é importante que a língua estrangeira seja abordada com o propósito de sensibilizar os alunos pequenos para a existência de outras línguas e outras culturas. Assim, apresentar a língua estrangeira de maneira natural, entre brincadeiras que são próprias para essa faixa etária, pode ser uma forma de garantir a motivação dos alunos para o aprendizado, além de não os sobrecarregar com a formalidade estrutural que verão num momento mais adequado, a partir do quinto, por exemplo.

Entretanto, ao proporcionar os primeiros contatos com o novo idioma, é conveniente que os professores estejam conscientes da importância que o lúdico tem na formação das crianças e que procurem a melhor forma de conduzir esses contatos, de modo a evitar dificuldades futuras na relação aluno-língua estrangeira. Como bem expõem Cunha e Nascimento (2005), quando a criança brinca expressa suas necessidades e desenvolve suas potencialidades por meio dos desafios constantes das situações lúdicas, o que provoca o pensamento, exercita habilidades e a leva a alcançar níveis de desempenho que só as ações por motivação intrínseca conseguem, porque brincando a criança aprende a engajarse nas atividades gratuitamente, sem visar recompensas ou temer punições.

Compartilhamos da mesma opinião de Boéssio (2005) e de Cunha e Nascimento (2005): se os primeiros contatos com a língua estrangeira não trouxerem prazer às crianças, estas poderão desenvolver um receio, uma tendência ao afastamento e, porque não dizer, uma repulsa contra outros idiomas e sua aprendizagem. Desenvolvida a repulsa, quando houver a necessidade de estudar uma língua estrangeira obrigatoriamente (ou seja, a partir do sexto ano do ensino fundamental), essa criança poderá vir a obter um desempenho insatisfatório que poderá ser-lhe prejudicial por toda sua vida.

Outra questão lançada por Solla (2005) diz respeito à utilidade do ensino da língua estrangeira para crianças de 6 a 10 anos. Tomando como exemplo o ensino de língua espanhola no Brasil em situação de fronteira ${ }^{2}$, o objetivo comunicativo pode e deve ser levado em conta como subsídio para a discussão sobre ensinar ou não língua estrangeira para crianças. Esses indivíduos mantêm contato estreito com falantes do castelhano e, por isso, supõe-se que seja conveniente que tenham a oportunidade de estudar esse idioma na escola.

Porém, a situação de fronteira não é a única ou principal preocupação nossa, posto que a inclusão do ensino do castelhano para crianças é crescente em várias outras localidades do país, como constatamos em nossa pesquisa. Em áreas não-fronteiriças como as regiões

${ }^{2}$ Como é o caso, por exemplo, de Foz do Iguaçu, município paranaense cujo governo municipal instituiu a obrigatoriedade da presença desse idioma no Ensino Fundamental I, ou da cidade fronteiriça Dionísio Cerqueira (SC), onde o então ministro da Educação Tarso Genro lançou o primeiro projeto de escola bilíngüe do Brasil 
Trab.Ling.Aplic., Campinas, 48(2), Jul./Dez. 2009

metropolitanas de Campinas (SP), São Paulo (SP), Rio de Janeiro (RJ), Porto Alegre (RS), por exemplo, há uma oferta crescente de língua espanhola para alunos das primeiras séries Ensino Fundamental em escolas particulares. Dessa forma, a segunda pergunta lançada por Solla poderia ser reformulada para: quais seriam os objetivos do ensino de espanhol para crianças em escolas de cidades não-fronteiriças?

Uma das finalidades desse ensino entendemos ser a oferta, aos alunos dos primeiros anos do ensino fundamental, de oportunidades de conhecer e melhor compreender culturas diferentes da sua, como propõem Boéssio (2005) e os PCNs, evitando o estigma do preconceito que aparece com frequência quando se tem contato com aquilo que é diferente. Outra finalidade é favorecer o surgimento e desenvolvimento de atitudes positivas dos alunos em relação ao processo de aprendizagem de uma língua estrangeira, o que pode levar os estudantes a encarar essa aprendizagem de forma significativa, prazerosa e motivadora, dependendo de como aconteça seu ensino.

\section{A REALIDADE DO ENSINO DE ESPANHOL PARA CRIANÇAS BRASILEIRAS}

Os cursos de Pedagogia incluem em seus programas diferentes disciplinas, leituras e atividades que objetivam oferecer ao futuro profissional informação e formação profunda acerca, entre outros aspectos, de teorias sobre o desenvolvimento infantil e sobre a aprendizagem; porém, não oferecem formação em língua estrangeira por não ser esse seu objetivo.

Os cursos de Licenciatura em Letras, por sua vez, ocupam-se da formação de professores de línguas, tanto materna quanto estrangeiras. Embora abordem temas relativos à aprendizagem em geral, centram-se nas teorias relacionadas à aprendizagem de idiomas por alunos a partir do $6^{\circ}$ ano.

Assim, ao se pensar no ensino de línguas estrangeiras a crianças constata-se que os conhecimentos que integram a base de ambos os cursos de formação mencionados são essenciais para o professor interessado em lecionar seja na Educação Infantil, seja nas séries iniciais do Ensino Fundamental. Contudo, não há a oferta de um curso que atenda a essas duas necessidades, fundamentais a nosso ver. Daí considerarmos que esse conhecimento deva ser adquirido por meio de uma formação específica, de modo a que se atenda adequadamente a uma demanda efetiva e crescente.

Assim, dada a existência da oferta do ensino de espanhol a crianças dos níveis citados em diferentes localidades brasileiras, interessou-nos conhecer qual era a formação dos docentes atuantes nesses espaços tendo em vista, como dissemos, a constatação da falta de cursos que habilitem professores de espanhol a trabalharem com crianças. Para tanto, nossa pesquisa procurou averiguar quem eram os professores que ministravam essas aulas e, além de informações acerca da sua formação, questionamos os profissionais sobre suas dificuldades bem como sobre as práticas de que eles se serviam para diminuir as eventuais dificuldades encontradas em sala de aula.

Constatamos que a maioria dos professores, sujeitos da nossa pesquisa (aproximadamente 92\%, ou seja, 12 - de 13), era licenciada em Letras, com habilitação em Espanhol. Além disso, aproximadamente 60\% (ou seja, 8) dos professores haviam cursado 
FERNÁNDEZ e RINALDI — Formação de professores de espanhol...

o Magistério no Ensino Médio e por volta de 40\% (ou seja, 5) haviam feito o Ensino Médio comum; apenas 23\% (ou seja, 3) fizeram pós-graduação e, desses, 2 se especializaram em Educação Infantil.

Em outra pesquisa atualmente em andamento, observamos um quadro um pouco diferente do anterior: há mais escolas que oferecem espanhol como língua estrangeira para crianças, porém os professores que aí atuam ainda não possuem qualificação adequada. Muitos dos docentes não possuem estudos superiores e consideram que para trabalhar com as crianças não é necessário possuir amplos conhecimentos da língua meta, pois acreditam que basta levar uma música ou fazer um jogo para agradar as crianças que elas aprenderão a língua estrangeira.

Entretanto, os professores licenciados, participantes da primeira pesquisa, afirmavam encontrar dificuldades vinculadas por eles às características individuais dos alunos: falta de atenção, falta de concentração e indisciplina. Em nenhum momento admitiram que suas dificuldades poderiam ter como causa práticas pedagógicas inadequadas ao nível escolar em que lecionavam, já que não possuíam capacitação, especialização ou conhecimentos específicos para ensinar a língua espanhola a crianças.

Apontaram, também, dificuldades relativas à organização e funcionamento dos cursos: pouca carga horária, falta ou precariedade de reuniões pedagógicas específicas de língua estrangeira, inadequação ou insuficiência de material didático do professor ou do aluno entre outros. Novamente, essas dificuldades não apresentavam qualquer relação com a prática docente. Antes, indicavam problemas de responsabilidade da instituição sobre os quais pouca ou nenhuma intervenção os professores poderiam ter.

Em contrapartida, poucas indicações diziam respeito a questões psicolinguísticas como as que envolvem a aquisição/aprendizagem de língua materna e/ou das línguas estrangeiras, ou seja, o processo de alfabetização/letramento, o domínio da metalinguagem, as interferências de uma língua sobre a outra etc. Inferimos que essas dificuldades não tenham sido citadas com muita frequência porque a maioria dos professores atuava com alunos a partir do $4^{\circ}$ ano (antiga $3^{\mathrm{a}}$ série), período no qual se supõe que o processo de alfabetização/letramento já esteja consolidado, ou porque talvez nem fossem capazes de identificar esse tipo de dificuldade por falta de conhecimento específico para lidar com crianças.

Por último, as dificuldades com menor índice de citação foram as que relacionam o idioma estrangeiro a aspectos psicológicos como, por exemplo, desinteresse do aluno frente à língua espanhola, ansiedade pelo conhecimento da língua escrita, vergonha de produzir a língua oral e antipatia pela língua estrangeira em questão. Em síntese, os alunos dos professores investigados não demonstravam preconceitos em relação ao novo idioma, o que confirmava nossa ideia inicial de que, se apresentássemos a língua espanhola nos primeiros anos da educação básica, poderíamos evitar que, posteriormente, os estudantes das séries finais do ensino fundamental ou os jovens vinculados ao ensino médio apresentassem visões negativas ou preconceituosas em relação à língua estrangeira e/ou aos seus falantes.

Nossa pesquisa evidenciou que os informantes não atribuíram muita importância às questões individuais dos alunos no que diz respeito ao processo de ensino e aprendizagem, atitude que, infelizmente, é muito comum e contrária ao que defendemos. A visão geral dos 
Trab.Ling.Aplic., Campinas, 48(2), Jul./Dez. 2009

sujeitos investigados sinalizava conceber os problemas como dificuldades referentes aos estudantes. Tal modo de encarar o assunto, de certa forma, exime o professor da responsabilidade de buscar alternativas e/ou caminhos que levem à superação dos problemas. Fernández Gálvez (2000), com quem concordamos, propõe uma mudança de posição: em vez de pensarmos em dificuldade de aprendizagem, devemos pensar em dificuldade de ensino. A partir dessa perspectiva, passamos a valorizar o aluno e o contexto em que se dá o processo de ensino e aprendizagem para podermos diagnosticar com mais segurança as dificuldades que surgem e, então, reorganizar nossa prática para tentar dirimir ou eliminar essas dificuldades. Entretanto, não é simples proceder a essa mudança de posição uma vez que isso exige refletir sobre as próprias práticas pedagógicas, crenças e atitudes e ser capaz de modificá-las de modo a contribuir para a melhoria do processo de ensinar e aprender.

Defendemos a ideia de que, para tornar possível tal mudança de olhar e de concepção, como sugere Fernández Gálvez, torna-se imprescindível que o professor conte com os subsídios adequados, isto é, com formação específica que lhe permita tanto a aproximação e o conhecimento de aspectos relacionados ao ensino e aprendizagem de idiomas quanto a reflexão sobre como direcioná-lo ao público infantil. Como veremos a seguir, os meios para alcançar esses propósitos ainda são escassos.

\section{INICIATIVASEXISTENTES}

No Brasil, em 2004, a Faculdade Paranaense (FACCAR), em Rolândia, PR, oferecia em seu curso de licenciatura em língua espanhola um ano de estudos sobre ensino e aprendizagem de língua estrangeira para crianças do Ensino Fundamental I. Em 2005, na Universidade Estadual de Campinas (UNICAMP), em São Paulo, houve, pelo menos, dois cursos de extensão sobre ensino de língua estrangeira para crianças, na modalidade inglês. Em 2008, a Universidade Estadual de Londrina (UEL), em Londrina, Paraná, ofereceu um curso de especialização (lato sensu) sobre o ensino de língua inglesa para crianças. A Faculdade de Educação da Universidade de São Paulo (FE-USP) também ofereceu, em 2008, um curso de extensão sobre ensino de espanhol para crianças e que teve boa repercussão. O resultado foi favorável a que outros cursos que abordem esse tema sejam propostos. Ainda na UEL, há um projeto individual de uma professora de língua espanhola configurado sob a proposta de um estágio voluntário voltado ao ensino e aprendizagem de língua espanhola para crianças do Ensino Fundamental I.

$\mathrm{Na}$ Espanha, na década de 80, o ensino de línguas estrangeiras começou a ser oferecido a crianças de dois a doze anos, sem que os professores fossem habilitados ou capacitados a atuarem nessa área. Aos poucos, o governo espanhol percebeu os problemas causados pela falta de formação adequada dos professores e passou a exigir que se inserissem nos cursos de formação de professores do ensino primário (o equivalente ao nosso Magistério Superior), as especialidades Francês e Inglês. O curso que habilita professores primários para esses dois idiomas chama-se Maestro Especialidad Lengua Extranjera, e é oferecido por diversas universidades. Essa carreira docente, na Espanha, oferecia também outras 
FERNÁNDEZ e RINALDI — Formação de professores de espanhol...

especialidades, como acontecia com a Pedagogia, no Brasil, antes da configuração vigente na atualidade.

Em 2004, a Universidad de León (Espanha) ofertou o primeiro curso de extensão universitária sobre ensino de espanhol para crianças, sob o título El desarrollo de las habilidades lingüísticas en Educación Infantil y en Educación Primaria. Esse curso visava instrumentar professores que já atuavam no ensino primário para receberem filhos de imigrantes, uma vez que a política educacional espanhola determina que essas crianças sejam integradas ao sistema educativo ao lado das crianças espanholas.

Em vista da implantação da Declaração de Bolonha a partir de 2010 no sistema educacional dos países membros da União Europeia, produziram-se várias mudanças na estrutura e nos planos curriculares dos cursos superiores. Um exemplo dos ajustes necessários no que se refere à formação de professores de línguas estrangeiras para crianças foi a inclusão de mais disciplinas relacionadas à área pedagógica no curso oferecido pela Universidad de Murcia, também na Espanha.

Como se constata, embora haja iniciativas variadas e pioneiras, elas ainda não são suficientes nem totalmente adequadas para atender à demanda e às reais necessidades educativas pois, quase sempre, são propostas isoladas e não sistemáticas.

\section{ALGUMASSUGESTÕES DE TRABALHO COM CRIANÇAS}

Estudos sobre jogos e brincadeiras (BROUGÈRE, 2004; KISHIMOTO, 2002) mostram a importância do lúdico no ensino de qualquer tema à criança e corroboram a hipótese de Krashen (1995) sobre a diferença entre aquisição e aprendizagem. Em vista disso, ainda que sem formação específica nem habilitado oficialmente, conviria ao professor que já atua com crianças, principalmente nos primeiros três anos do Ensino Fundamental, período em que o processo de alfabetização/letramento ainda não está consolidado, apoiar suas aulas em atividades lúdicas (RINALDI, 2000).

Entre as muitas propostas que podem ser formuladas, a audição, em língua espanhola, de contos de fadas familiares às crianças, pode configurar-se como um triplo auxiliar da aprendizagem: enquanto ouvem a história aprendem a língua estrangeira; a partir dela poderão compreender melhor alguma questão pessoal que estejam vivendo (BETTELHEIM, 2006) e, ainda, poderão se divertir ao reviver, em outro idioma, histórias já conhecidas.

Outras atividades, além da audição, podem ser preparadas e executadas a partir de contos. Jogo de personagens (teatro), atividades manuais que tenham como inspiração o conto (desenho espontâneo, pintura, modelagem) são produções que demonstram a compreensão da criança sobre o que ouviu. Essa estratégia é propícia com crianças não alfabetizadas/não letradas ou em fase de alfabetização/letramento.

Canções folclóricas, trava-línguas e parlendas são outras fontes riquíssimas de recepção e produção oral infantil, pois as rimas facilitam a memorização. É possível solicitar às crianças que cantem ou declamem pequenas poesias sem esquecer, evidentemente, de oferecer-lhes o significado do que ouvem ou dizem. 
Trab.Ling.Aplic., Campinas, 48(2), Jul./Dez. 2009

Os jogos cooperativos (mais do que os jogos competitivos) também são uma importante estratégia de ensino de língua estrangeira para crianças. O convite ao jogo, por si só, já atua no que Krashen (1995) denominou filtro afetivo: a motivação da criança aumenta e a ansiedade tende a diminuir, fatos que auxiliam a aquisição de LEs.

\section{CONSIDERAÇÕES FINAIS}

Tendo em vista a realidade do ensino de espanhol para crianças no Brasil anteriormente apresentada, fica clara a necessidade de ações concretas e amplas que conduzam a uma adequada formação e capacitação dos docentes que atuam nesse segmento.

Entendemos que as experiências espanholas já mencionadas, transferidas e adaptadas à nossa realidade, podem ser uma possibilidade de minimizar os efeitos, muitas vezes negativos, de uma formação inadequada de professores de língua estrangeira para crianças. Nesse sentido, tal formação pode ocorrer por meio da inclusão de alguns componentes curriculares relacionados ao estudo e ao ensino de língua estrangeira para esse público em cursos como a Pedagogia, que habilita profissionais a atuarem com as crianças de Educação Infantil e Ensino Fundamental I.

Entretanto, no caso brasileiro, há alguns empecilhos. Além de os alunos que chegam à Universidade normalmente não serem competentes na língua estrangeira que desejam ensinar, a estrutura atual do curso de Pedagogia, ao que parece, não comporta novos conteúdos. Embora tenhamos plena consciência de que não é o caminho ideal, ainda assim poderia ser oferecida uma disciplina optativa que abordasse questões relacionadas ao ensino e aprendizagem de LEs a crianças, ao menos como medida paliativa para propiciar a discussão acerca das principais dificuldades com as quais se deparam muitos profissionais.

Outra possibilidade, que não elimina a anterior, diz respeito à inclusão de alguns temas referentes ao ensino de língua estrangeira para crianças nos programas de Metodologia (ou Prática) de Ensino dos cursos de Licenciatura em línguas estrangeiras. Porém, essa alternativa não habilitaria oficialmente os professores para atuarem com esse público, já que a legislação em vigor os autoriza apenas a atuarem no Ensino Fundamental II e no Ensino Médio, como mencionamos.

Por fim, temos como terceira opção a criação de um curso de especialização voltado para o ensino de língua espanhola a crianças, com componentes curriculares compatíveis com esse tema, especificamente, que atendam às necessidades dos professores que já atuam nesses níveis escolares ou que queiram iniciar seu trabalho com esse público.

De qualquer modo, é imprescindível que essa discussão se desenvolva na direção de tornar oficial a oferta de cursos de formação de professores de língua estrangeira para crianças, em especial de espanhol, idioma que nos ocupa. Apesar de a legislação não contemplar a obrigatoriedade do ensino de LEs nesse nível, na prática ele vem sendo incorporado por mais escolas a cada dia. Portanto, entendemos que seja este o momento ideal para (re)pensar a formação e qualificação docente assim como as correspondentes e necessárias alterações nos textos legais. 
FERNÁNDEZ e RINALDI — Formação de professores de espanhol...

\section{REFERÊNCIASBIBLIOGRÁFICAS}

ABRAHÃO, M.H.V., ALMEIDA FILHO, J.C.P.de, BOHN, H.I. (Comissão de redação) (2000). Carta de Pelotas. Florianópolis: Ipol.

BETTElHEIM, B. (1980). A psicanálise dos contos de fadas. 20.ed., Rio de Janeiro: Paz e Terra, 2006.

BROUGÈRE,G. (1998). Jogos e educação. Porto Alegre: Artes Médicas.

BOÉSSIO, C.P.D.(2005). Uma prática reflexiva do ensino de Espanhol nas séries iniciais, http:// www.cce.ufsc.br/ 1le/congresso/trabalhos_lingua/Cristina\%20Pureza\%20Duarte\%20Boessio.doc, acessado em 02.05.2005.

BRASIL. (1996). MEC. LEI de Diretrizes e Bases da Educação Nacional Lei no 9.394, de 20 de dezembro.

BRASIL. (1999). Ministério da Educação. Secretaria de Educação Média e Tecnológica. Parâmetros curriculares nacionais, códigos e suas tecnologias. Língua estrangeira moderna. Brasília: MEC, 1999. pp 49-63.

BRASIL.(1998). Secretaria de Educação Fundamental. Parâmetros Curriculares Nacionais: terceiro e quarto ciclos do ensino fundamental: língua estrangeira/ Secretaria de Educação Fundamental, Brasília, MEC/SEF.

CAMERON, L. (2001). Teaching languages to young learners. Cambridge: Cambridge United Press.

CARRANZA, M.G. (2002). Lenguas extranjeras en Educación Infantil. Manual Didactico. s/1, Calipso.

CHOMSKY, N. (1987). On the Nature, Use, and Acquisition of Language. In: CHOMSKY, N._Generative grammar: its basis, development and prospects. Kyoto: Kyoto University of Foreign Studies.

CUNHA, N.H.S. e NASCIMENTO, S.K.do. (2005). Brincando, aprendendo e desenvolvendo o pensamento matemático. Petrópolis: Vozes.

DECLARAÇÃO de Bolonha (1999), disponível em: http://www2.ull.es/docencia/ creditoeuropeo/ bolonia.pdf, acessado em 15.06.2009.

FALCÃO, G.M. (1984). Psicologia da aprendizagem. São Paulo: Ática.

FERNÁNDEZ GÁLVEZ, J.D. (2000). ¿Qué cambia al pensar en "problemas de enseñanza” en vez de "problemas de aprendizaje"? in: Alas para Volar. I Congreso Internacional de Necesidades Educativas Especiales. Granada: Ediciones Adhara. (vol.2).

HARPAZ, Y. (2002). Myths and misconceptions in cognitive science. Human cognition in the human brain. http://human-brain.org/myths.html. Acessado em 13.12.2005.

JALLES, A.F. (2003) La Adquisición del Lenguaje Infantil en un Contexto Bilingüe. Madrid: Universidad Complutense de Madrid. Tese de doutorado.

KISHIMOTO, T.M. (org.) (2002). O brincar e suas teorias. São Paulo: Pioneira Thomson Learning.

KRASHEN, S.D. (1995). Principles and practice in second language acquisition. Hertfordshire: Phoenix ELT.

LENNEBERG, E. (1981). Fundamentos biológicos del lenguaje. 2.ed., Madrid: Alianza. 
PIAGET, J (1967). Seis estudos de Psicologia, Rio de Janeiro: Forense.

RAPPAPORT, C.R. et al. (1981). Psicologia do desenvolvimento. São Paulo: EPU. (vol.1, 3, 4)

RINALDI, S. (2000). As estratégias de ensino de espanhol em sala de aula para alunos de Ensino Fundamental I - 8-9 anos, FE-USP. (monografia apresentada ao final do curso de Licenciatura, disciplina Metodologia do Ensino de Espanhol).

. (2006). Um relato da formação de professores de Espanhol como Língua Estrangeira para crianças: um olhar sobre o passado, uma análise do presente e caminhos para o futuro. Dissertação de mestrado. Faculdade de Educação. Universidade de São Paulo.

RODRIGUES, L. A. D (2005). Dos fios, das tramas e dos nós: a tessitura da rede de crenças, pressupostos e conhecimentos de professores de inglês que atuam no Ciclo I do Ensino Fundamental. Tese de doutoramento. Faculdade de Educação. Universidade de São Paulo.

SCHÜTZ, R. (2004). A Idade e o Aprendizado de Línguas. English Made in Brazil <http://www.sk.com.br/ sk-apre2.html>. Acessado em 03.05.2005.

SOLLA, M.L. (2005). Uma prenda de Natal ou o 'Papai Noel entrou pela porta dos fundos'. http:// www.setubalnarede.pt/content/index.php?action=articlesDetailFo\&rec=615. Acessado em 11.06.2009.

VYGOTSKI. L.S. (1993). Pensamento e linguagem. São Paulo: Martins Fontes. 